\title{
Study of a bacterial community in the aquaponic closed-loop system of Gembloux Agro-Bio-Tech
}

Mathilde Eck, Sébastien Massart, Haïssam Jijakli

Integrated and Urban Plant Pathology Laboratory mathilde.eck@uliege.be 


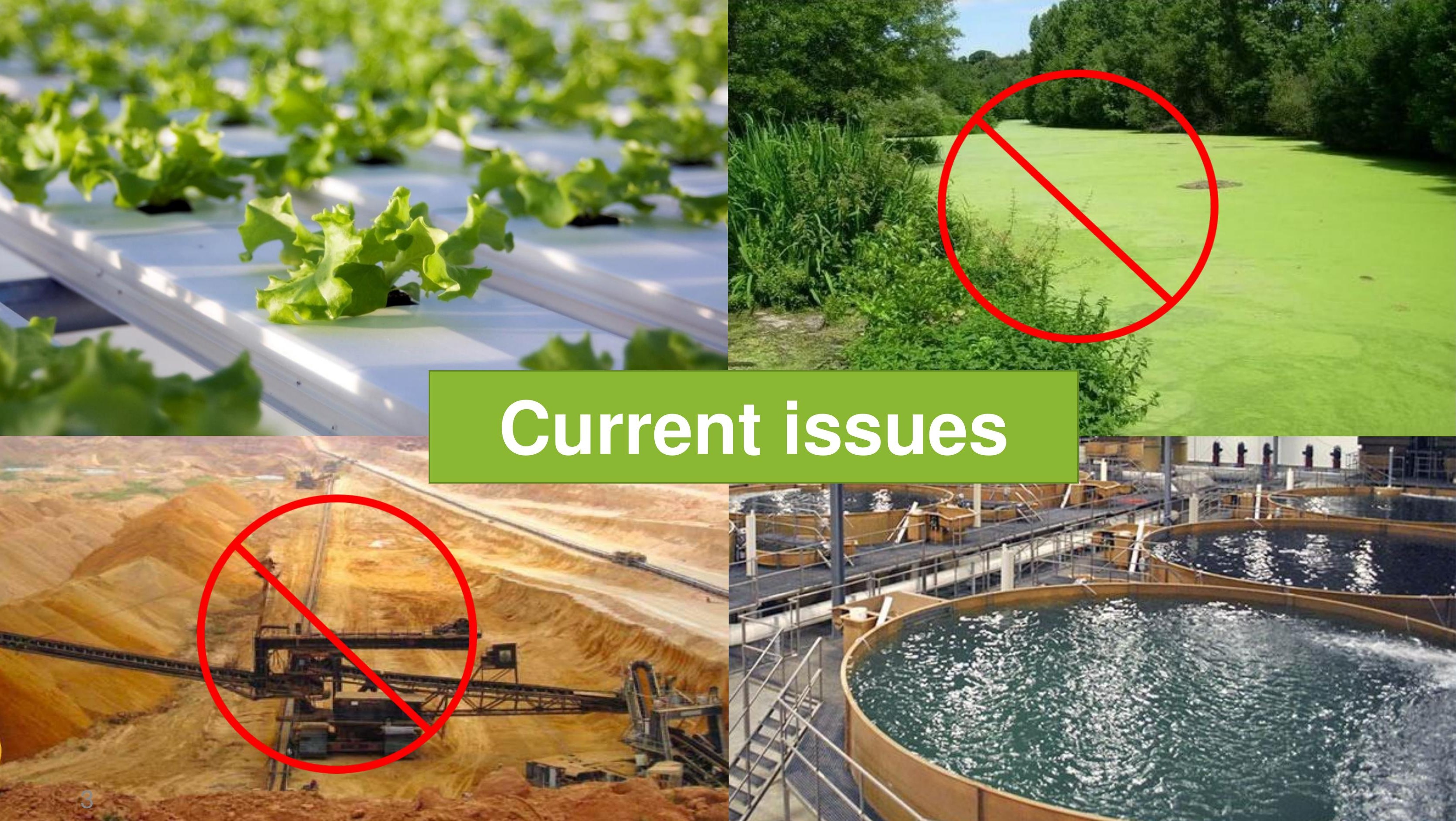




\section{An innovative solution: aquaponics}

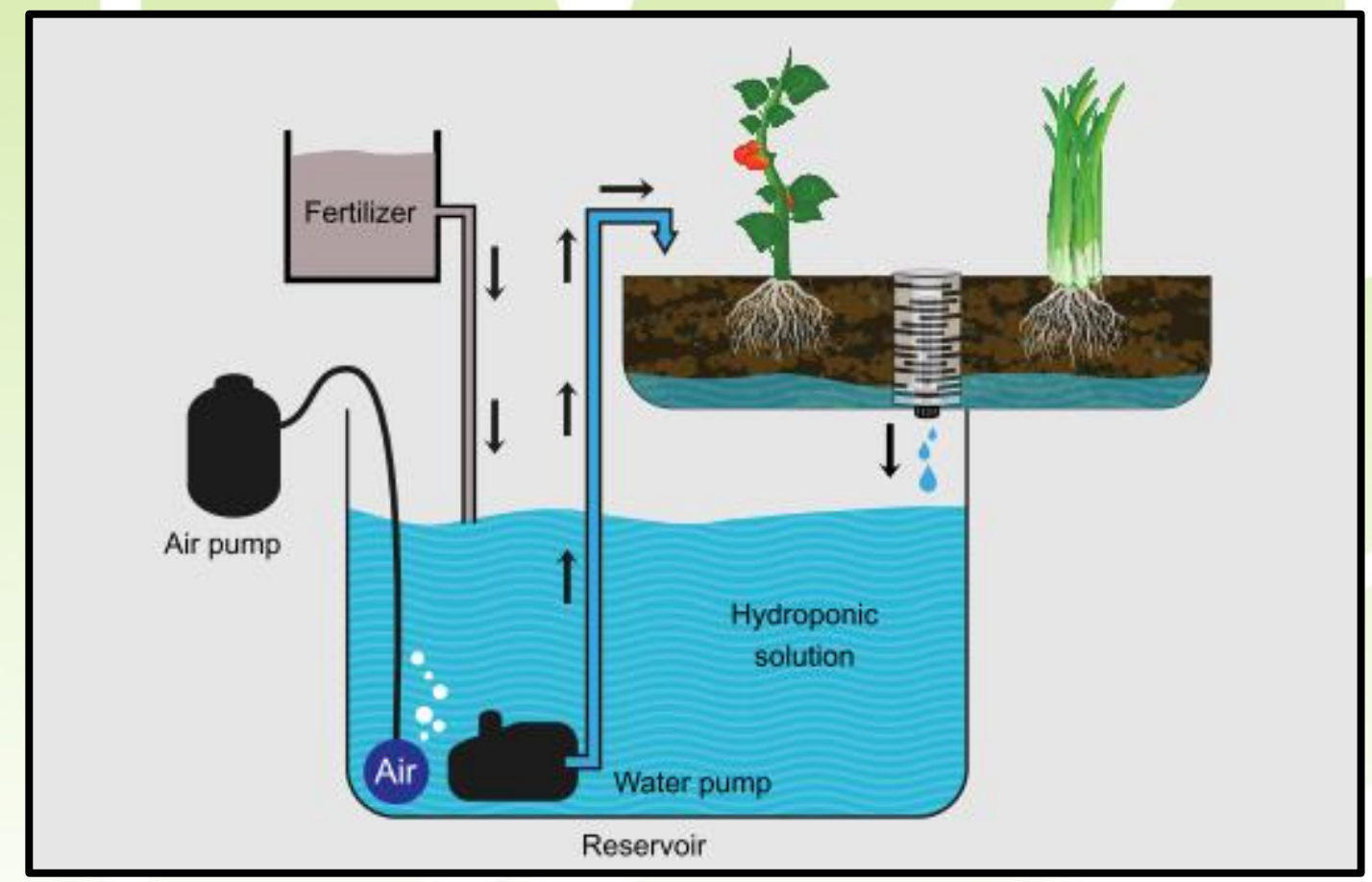

Hydroponics

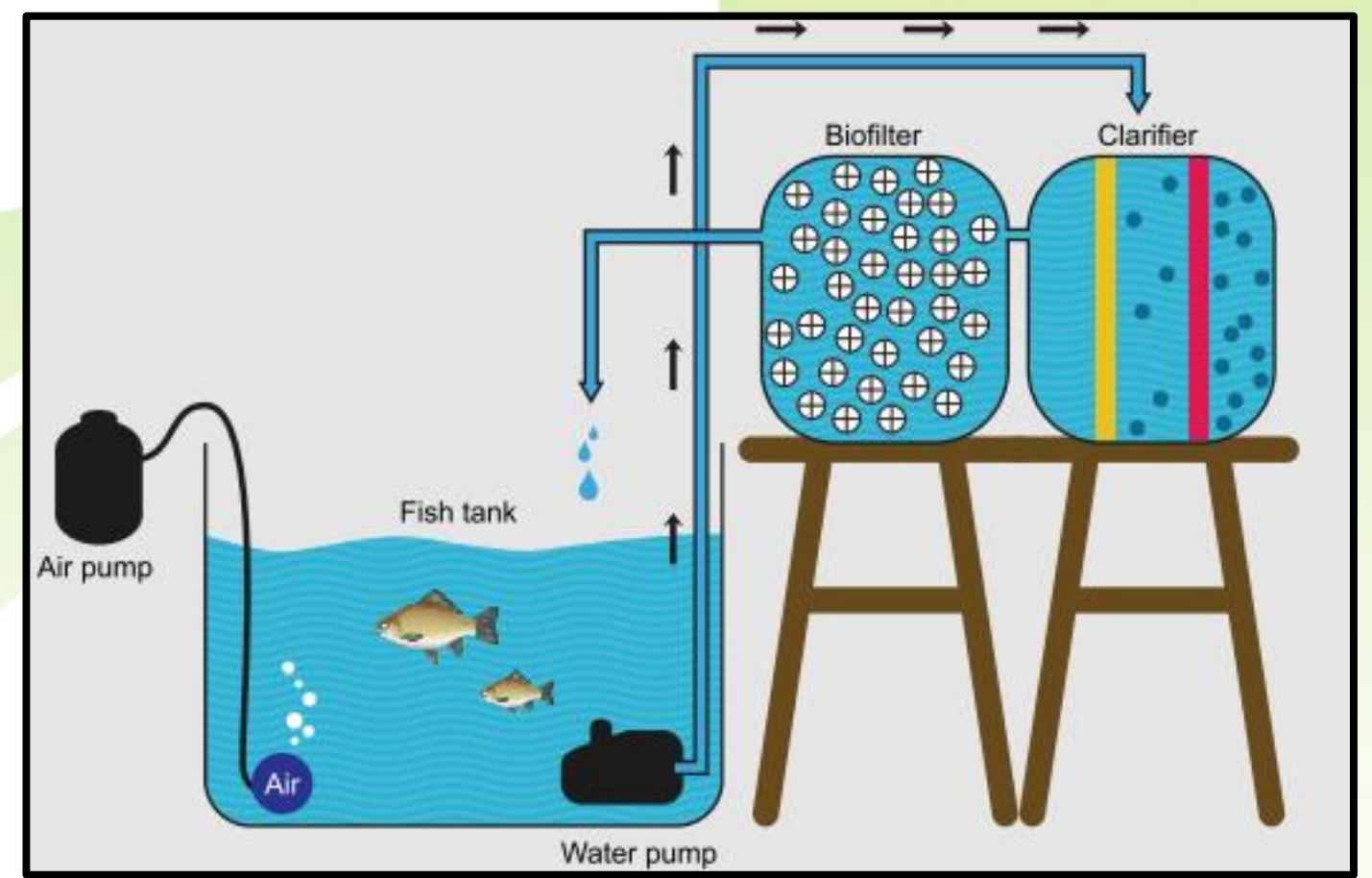

Aquaculture 


\section{An innovative solution: aquaponics}

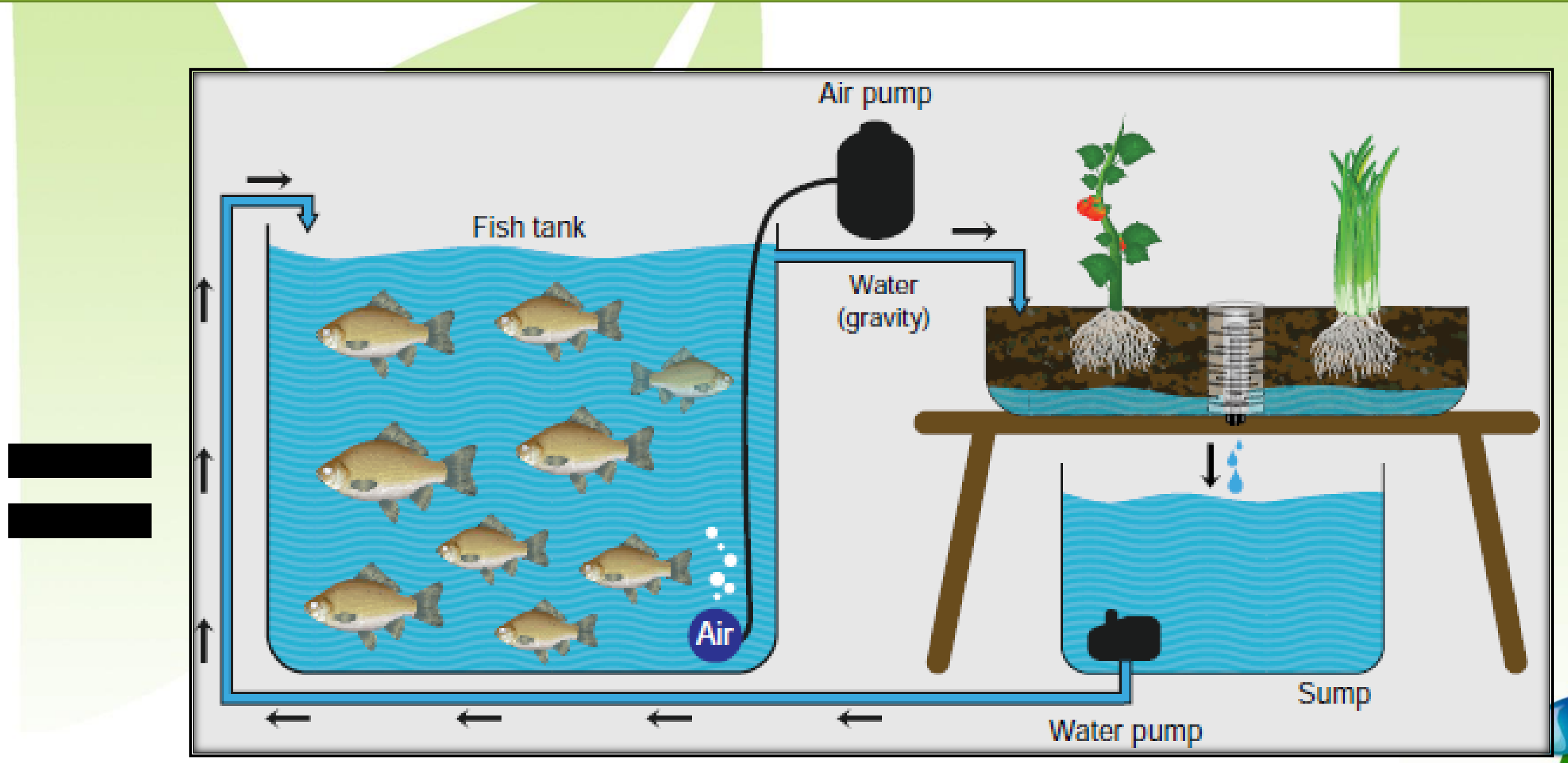




\section{An innovative solution: aquaponics}

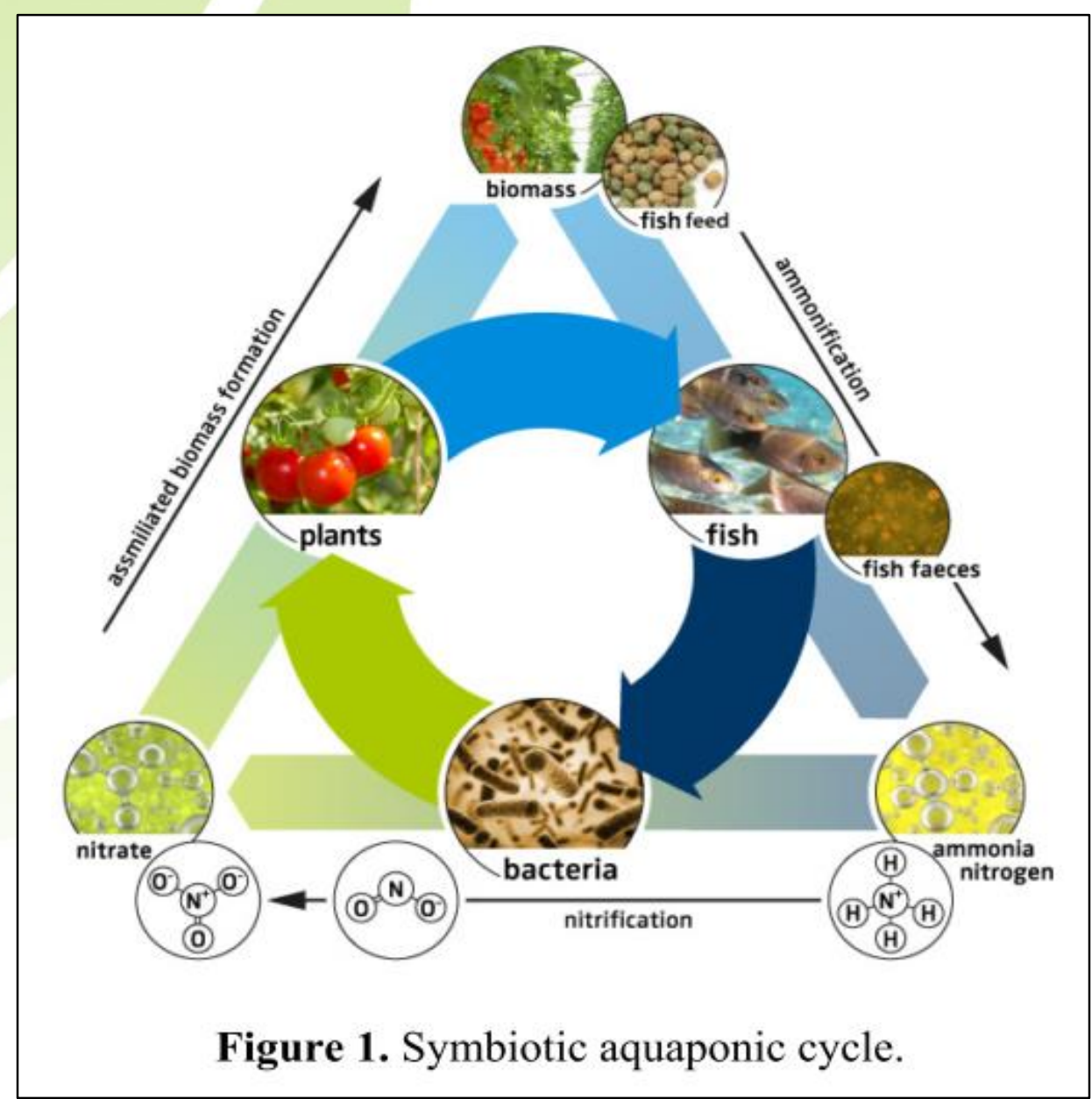




\section{Microorganisms in aquaponics}

Nitrifying bacteria

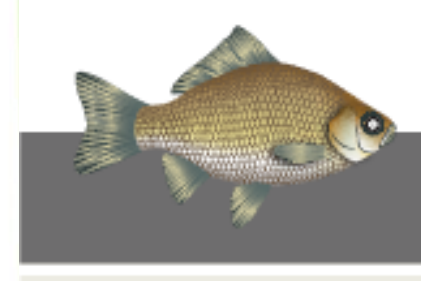

Fish produce ammonia in waste

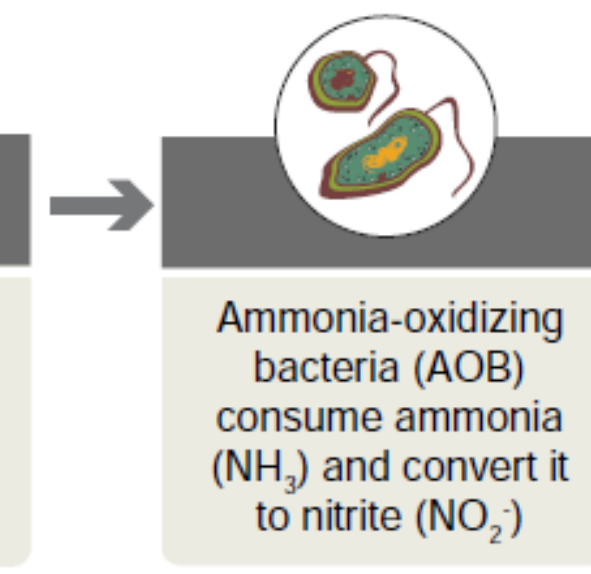

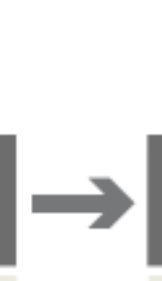

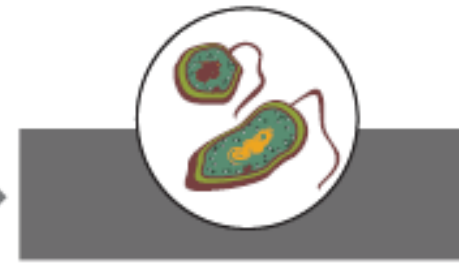

Nitrite-oxidizing bacteria (NOB) consume nitrite $\left(\mathrm{NO}_{2}{ }^{-}\right)$and convert it into nitrate $\left(\mathrm{NO}_{3}{ }^{-}\right)$
AOB

Nitrosomonas,

Nitrosococcus,

Nitrosospira

\section{NOB}

Nitrobacter,

Nitrococcus,

Nitrospina,

Nitrospira

\section{Non nitrifying bacteria}
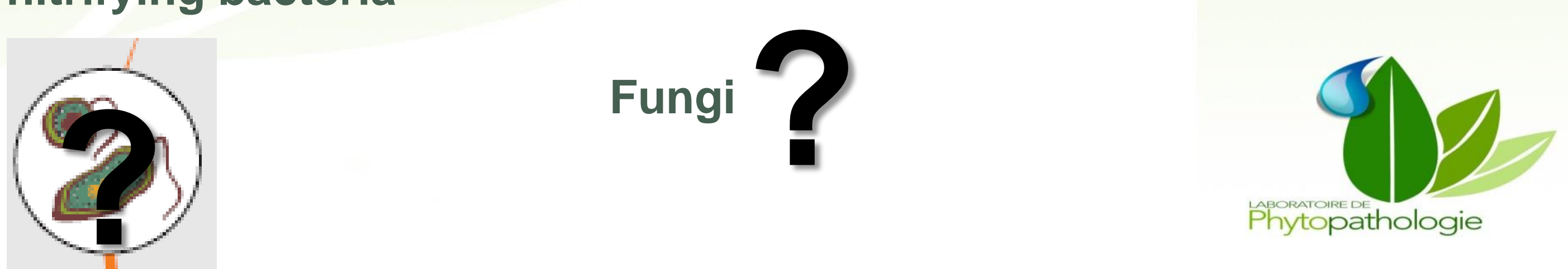

Somerville et al., 2014 


\section{Why studying microorganisms in aquaponics?}

\section{AQUAPONCSCYCLE}

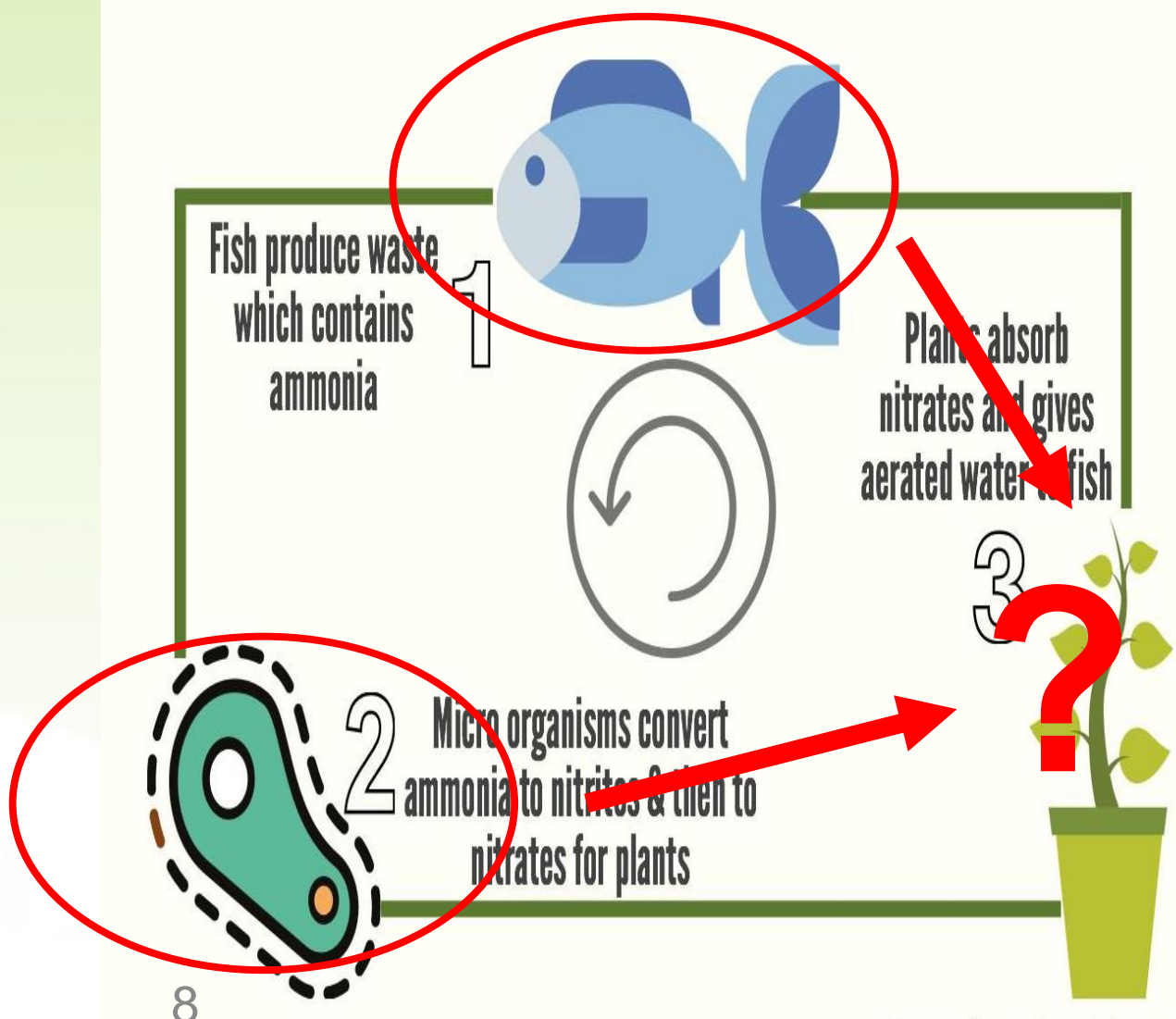

Similar yields in aquaponics and hydroponics despite an aquaponic solution containing lower nutrients concentrations

Delaide et al., 2016

Goddek et al., 2015

Rakocy et al., 2004

Seawright et al., 1998 


\section{Plant and Fish Farming Box}

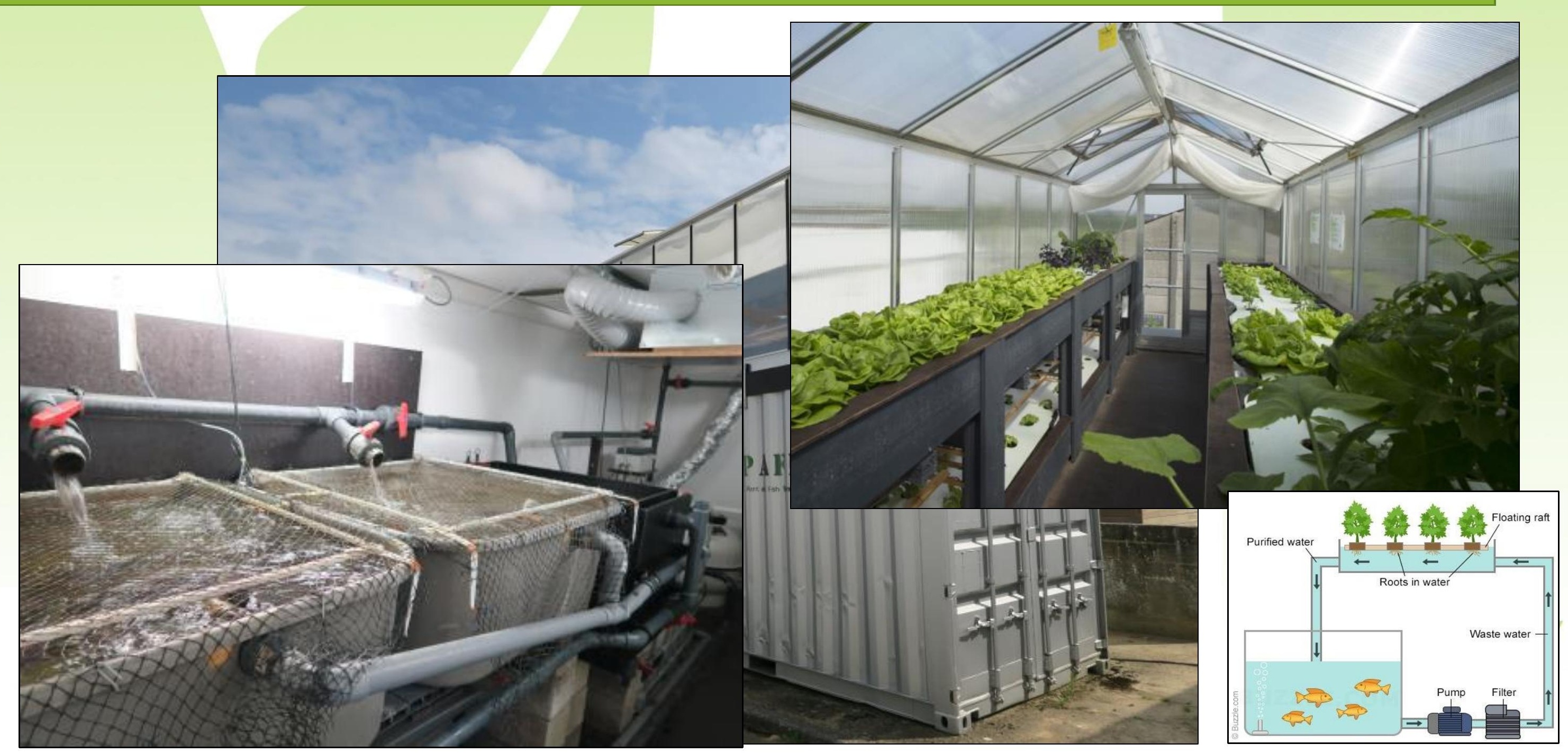




\section{Goals}

$\rightarrow$ First idea of the composition of the community?

$\rightarrow$ One or several communities? Comparison?

$\rightarrow$ Does it evolve or is it static? 


\section{Method: sampling}

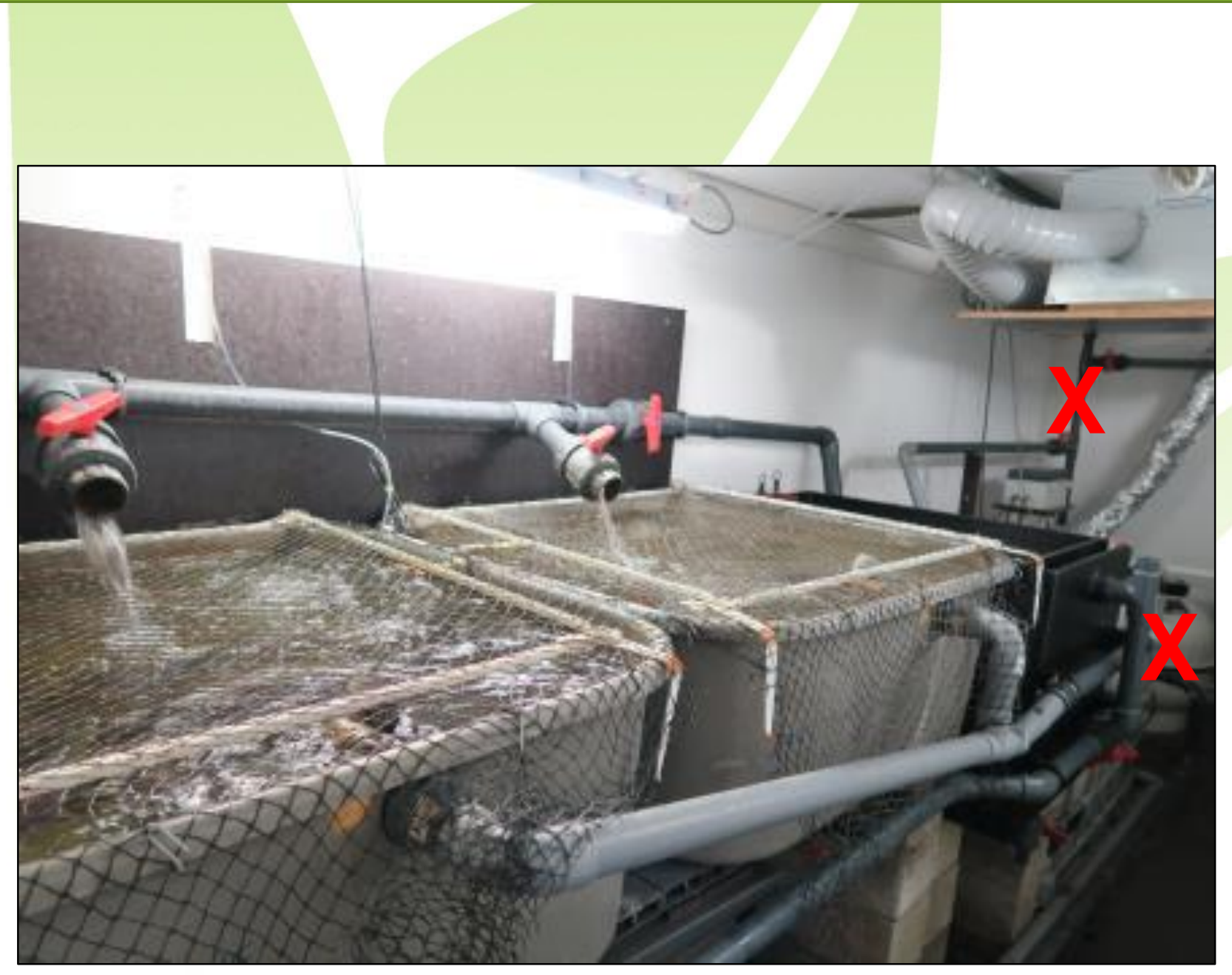

$\rightarrow 4$ technical replicates

$\rightarrow$ once a week

$\rightarrow 3$ weeks

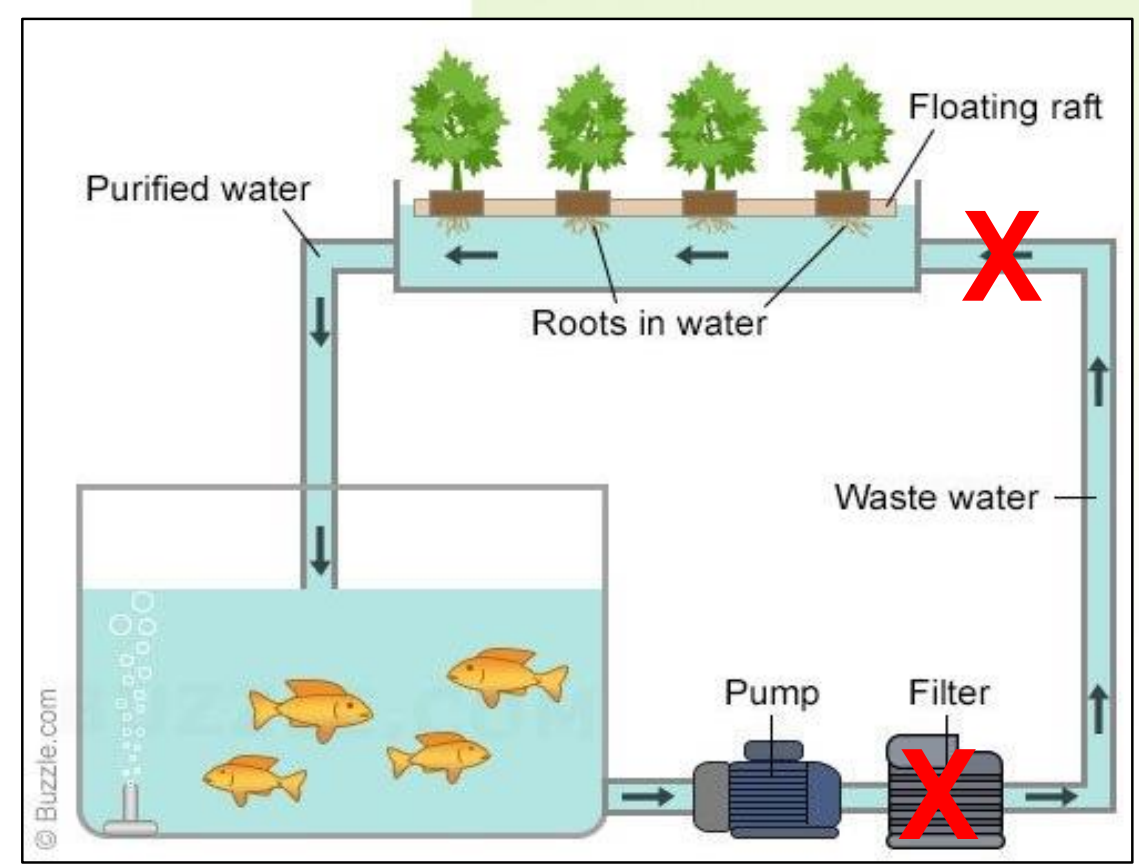




\section{Method: preparation, sequencing and data analysis}

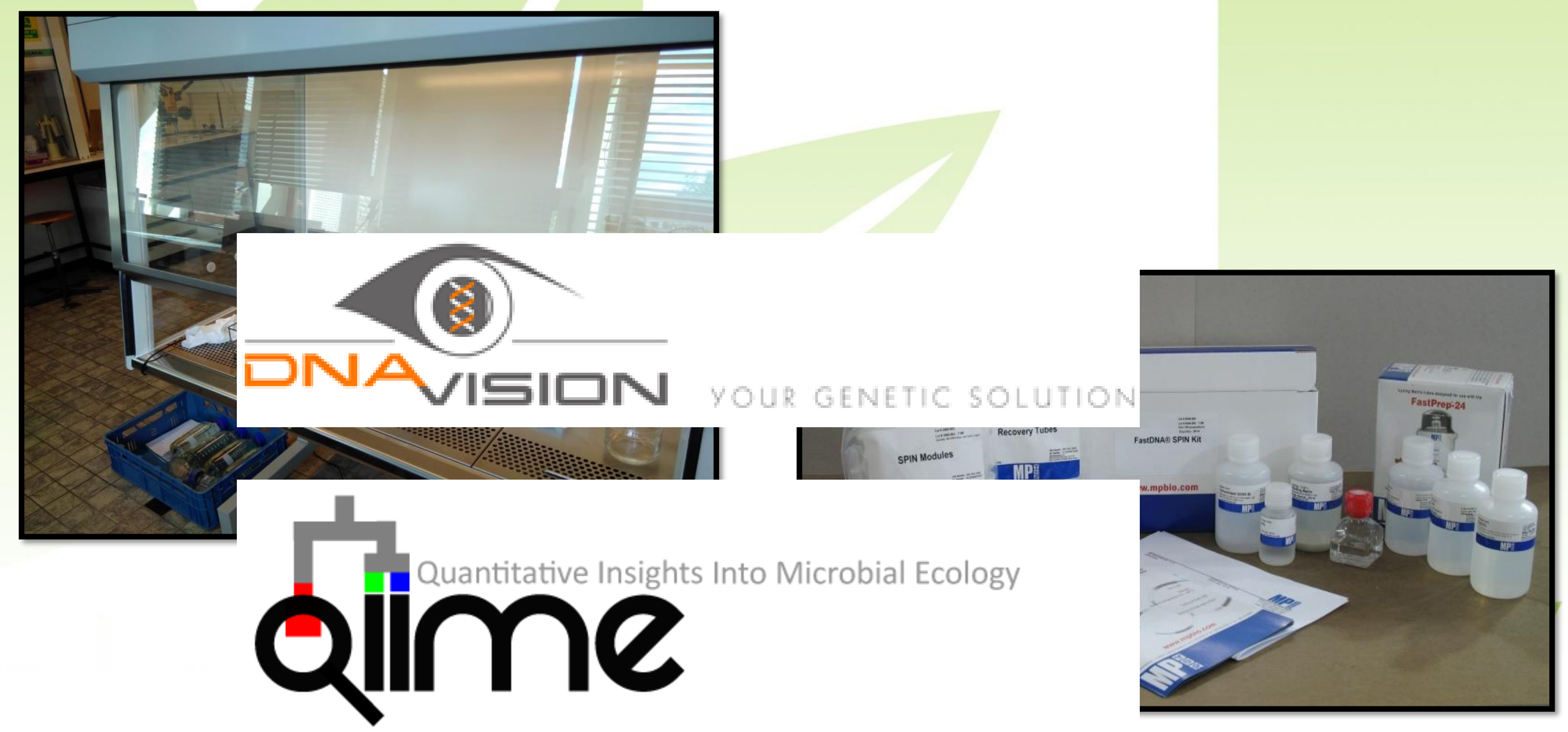




\section{Composition}

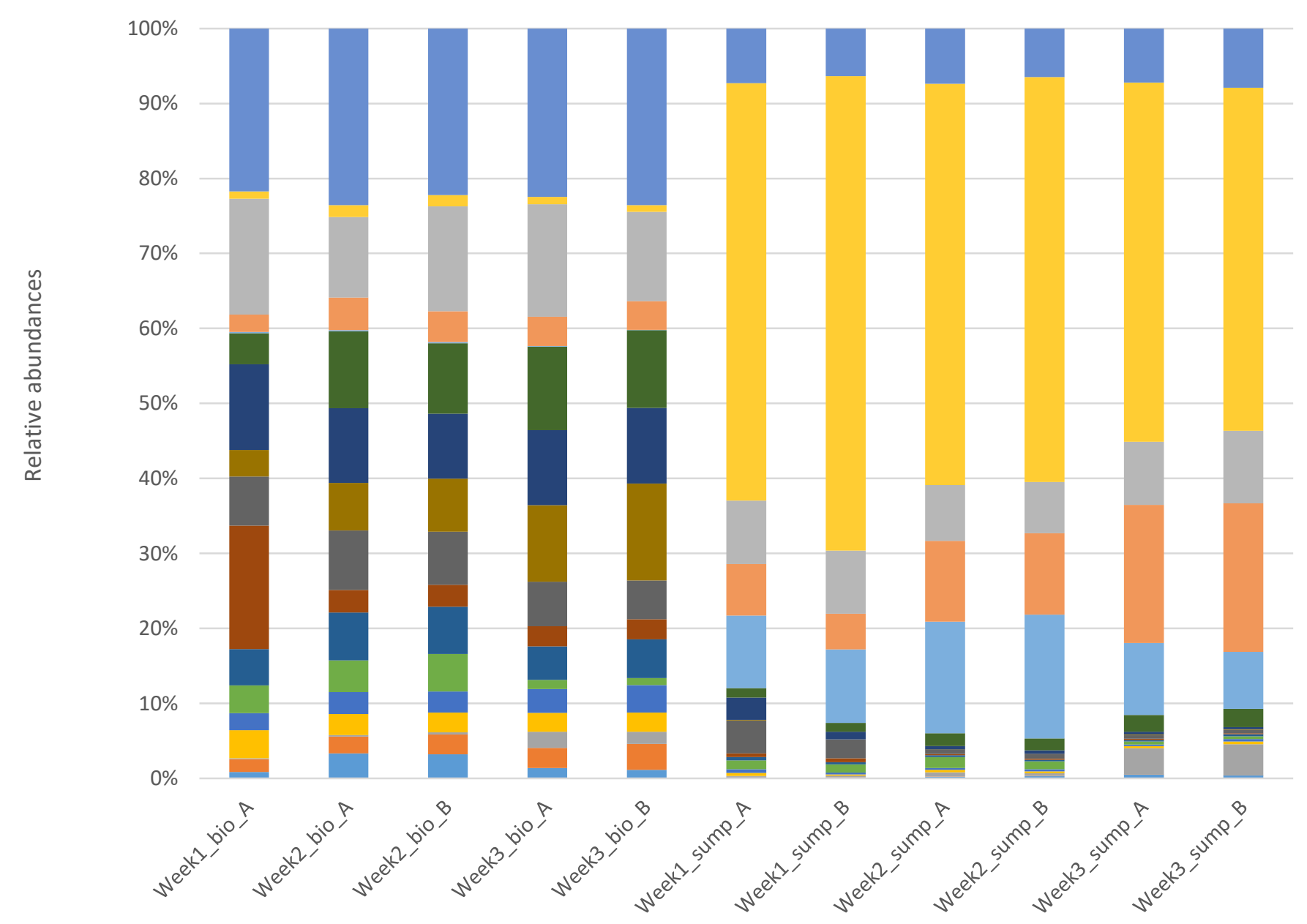

Others

Novosphingobium

- Unassigned

n Unassigned (Rhizobiales)

nagnetospirillum

- Unassigned (Alphaproteobacteria)

- Rhodospirillaceae

- Unassigned (Chloracidobacteria, PK29)

- Unassigned (Chlorobi, OPB56)

- Unassigned (Phycisphaerales)

Hyphomonadaceae

Hyphomicrobiaceae

- Rhodobacter

Rhodobacteraceae

- Unassigned (GN02)

Unassigned (Solibacterales)

- Unassigned (Myxococcales, OM27)

Fig.1. Bacterial composition of samples 


\section{Different communities in one system}

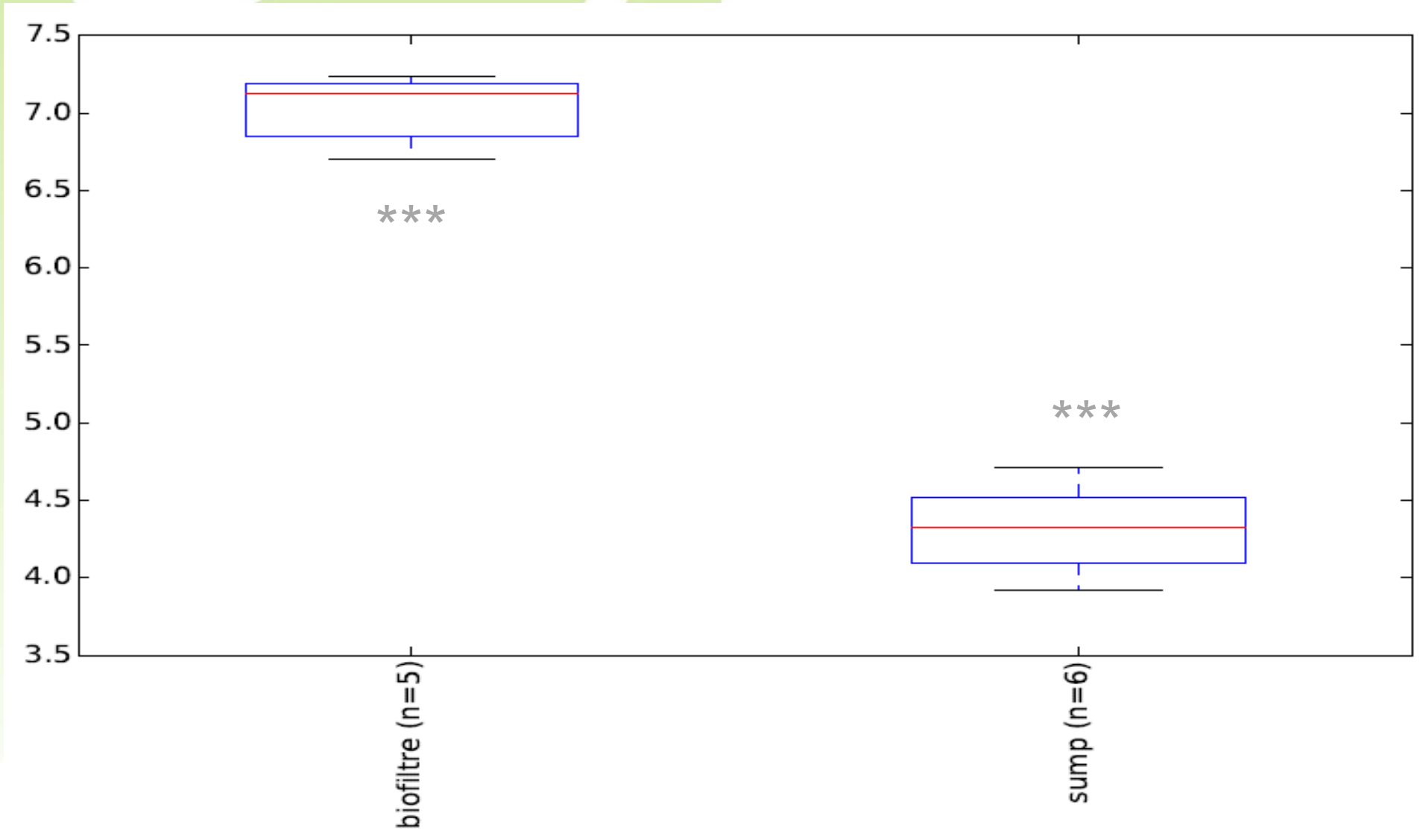

Fig.2. Box plots comparing the Shannon indices of the biofilter samples and sump samples 


\section{Stable communities}

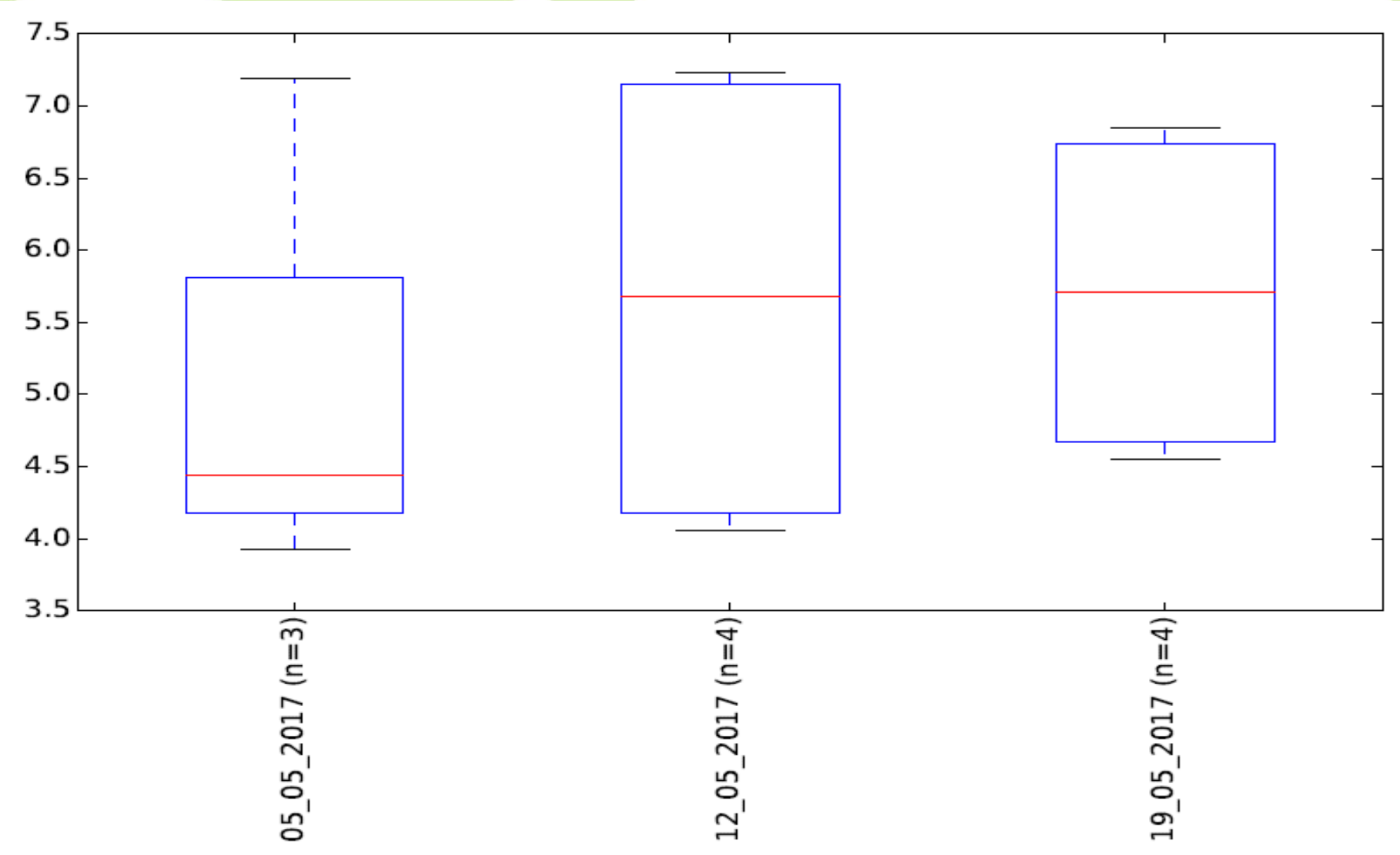

Fig.3. Box plots comparing the Shannon indices of the three sampling dates. No significant 


\section{Conclusions}

- Different communities in one system (sump and biofilter)

- Biofilter community is more diverse

- Communities look stable over time

- Perspectives

$>$ More thorough characterisation of communities

$>$ Comparison of communities in different systems

$>$ Understanding of the functions of microorganisms 


\section{Thank you for your attention}

All questions are now welcome 